\title{
Larvicidal efficacy of Cryptomeria japonica leaf essential oils against Anopheles gambiae
}

\author{
France P Mdoe', Sen-Sung Cheng ${ }^{2}$, Lucile Lyaruu ${ }^{3}$, Gamba Nkwengulila', Shang-Tzen Chang ${ }^{4}$ \\ and Eliningaya J Kweka ${ }^{3,5^{*}}$
}

\begin{abstract}
Background: Alternative insecticidal compounds with mortality effect against mosquito life cycle stages are currently needed. The compounds should be biodegradable and nontoxic to non-targeted insects. Plant based larvicides provide effective control of vector populations. This study explored Cryptomeria japonica leaf essential oil larvicidal potency against Anopheles gambiae sensu stricto.

Methods: Essential oils (12.5 to $200 \mu \mathrm{g} / \mathrm{mL}$ ) extracted from C. japonica leaves were evaluated against An. gambiae s. s. larvae in both the laboratory and semi field in 6 replicates for each dose. Larval mortality readings were taken at $12,24,48$, and $72 \mathrm{~h}$ post treatment.

Results: C. japonica leaf essential oil yield was $17.06 \pm 0.56 \mathrm{~mL} / \mathrm{kg}$ and $1.60 \pm 0.33 \%$ (w/w). GC-FID and GC-MS analyses revealed 22 constituents. Essential oil was more effective against An. gambiae s.s. larvae in the laboratory than in semi field trials. Mortality increased with increasing dosages (12.5 to $200 \mu \mathrm{g} / \mathrm{mL}$ ) in the laboratory (31.75 to 100\%) and semi field trials (17.75 to 99.5\%), respectively. The $L C_{50}$ value ranged from 5.55 to $63.92 \mu \mathrm{g} / \mathrm{mL}$ in the laboratory, and 8.22 to $134.84 \mu \mathrm{g} / \mathrm{mL}$ in semi field conditions, $L C_{90}$ value ranged from 41.34 to $205.93 \mu \mathrm{g} / \mathrm{mL}$ in the laboratory and 50.92 to $213.11 \mu \mathrm{g} / \mathrm{mL}$ in semi field conditions.

Conclusion: This study has demonstrated the potential of $C$. japonica leaf essential oil to cause mortality effects to An. gambiae s. s. larval populations, however, further studies need to be conducted under field conditions and also with individual active compounds of C. japonica essential oil.
\end{abstract}

Keywords: Cryptomeria japonica, Larvicidal efficacy, Anopheles gambiae s.s, Mortality, Essential oil

\section{Background}

An. gambiae s.s. is the most effective and efficient vector of the most lethal malaria parasite species (Plasmodium falciparum) that predominates Africa, a region where almost $90 \%$ of worldwide malaria deaths occur [1,2]. The transmission of malaria is through a bite by an infected female mosquito [3]. Some deliberate interventions are being implemented to get rid of human vector contact, in Africa, insecticide treated bed nets (ITNs) and indoor residual spraying (IRS) are the key interventions [2]. However, the on-going interventions are threatened by

\footnotetext{
* Correspondence: pat.kweka@gmail.com

${ }^{3}$ Division of Livestock and Human Diseases Vector Control, Tropical Pesticides Research Institute, Ngaramtoni, Off Nairobi Road, P.O. Box 3024, Arusha,

Tanzania

${ }^{5}$ Department of Medical Parasitology and Entomology, Catholic University of Health and Allied Sciences, P.O. Box 1464, Mwanza, Tanzania

Full list of author information is available at the end of the article
}

the emergence and spread of resistance genes among mosquito species populations to major insecticides classes such as pyrethroids as well as carbamates and organophosphates to a lesser extent [4]. Therefore, targeting vector mosquitoes at the larval stage is the best alternative since larvae are relatively immobile and confined within a given geographical area, cannot change behaviour to escape the effects of insecticides and thus become more vulnerable as compared to adult mosquitoes [5]. Nevertheless, malaria vector control using synthetic insecticides is also challenged by the insecticidal effects of nontargeted organisms and environmental pollution [6].

Plants constitute a rich source of active and effective compounds that are biodegradable and have traditionally been used to control mosquitoes [7-9]. The complex and variable mixtures of bioactive compounds with different modes of action, offered by plants, may lessen the chance 
of resistance in mosquito populations. The Japanese cedar (Cryptomeria japonica D. Don) leaf essential oil has revealed excellent larvicidal efficacy against Aedes aegypti and Ae. albopictus, furthermore, the major constituents of the leaf essential oil were effective and displayed various degrees of efficacy when tested individually against larvae of both Ae. aegypti and Ae. albopictus [10]. Kannathasan and others pointed out that, vector resistance against plant-based insecticides is not yet reported at the moment [11]. Therefore, searching for plant-based pesticides is of paramount importance in vector control and in overcoming the prevailing vector resistance challenges. This study focused on evaluation of C. japonica leaf essential oil efficacy against $A n$. gambiae s.s. larvae in the struggle to develop an effective, environmentally friendly larvicide and target specific plant-based pesticides that human malaria vector mosquitoes have not developed resistance to.

\section{Methods}

\section{Plant material}

Fresh mature leaves of 28-year-old Japanese cedars $(C$. japonica D. Don) were collected in August 2009 from the Experimental Forest of the National Taiwan University located in the Nantou County in Central Taiwan (longitude: $120^{\circ} 57^{\prime} 56.51^{\prime \prime} \mathrm{E}$; latitude: $24^{\circ} 00^{\prime} 46^{\prime \prime} \mathrm{N}$; elevation: $600 \mathrm{~m}$ ). A voucher specimen (CJL006) has been deposited with the Laboratory of Wood Chemistry (School of Forestry and Resource Conservation, National Taiwan University).

\section{Isolation of essential oils}

Fresh mature leaves (200 g) of C. japonica were subjected to hydrodistillation (HD) using a Clevenger-type apparatus [12] for $6 \mathrm{hrs}$. Their oil content in percentage (w/w) and $\mathrm{mL} / \mathrm{kg}$ were determined on the basis of the leaf dry weight. Each test was replicated three times and the essential oils were stored in dark vials at $4^{\circ} \mathrm{C}$ until further analysis.

\section{GC-FID analysis}

The C. japonica leaf essential oils obtained by the two different extraction methods were analyzed with a Finnigan Trace GC apparatus equipped with a flame ionization detector (FID) and a DB-5 cap. Column (30 m $\times 0.25 \mathrm{~mm}$ i.d., film thickness $0.25 \mu \mathrm{m}$ ). The oven temperature was programmed isothermally at $50^{\circ} \mathrm{C}$ for $2 \mathrm{~min}$ and was then increased from $50^{\circ} \mathrm{C}$ to $250^{\circ} \mathrm{C}$ at $5^{\circ} \mathrm{C} / \mathrm{min}$; injector temperature, $270^{\circ} \mathrm{C}$; carrier gas, $\mathrm{He}(1 \mathrm{~mL} / \mathrm{min})$. The samples $(1 \mu \mathrm{L})$ were injected neat with a 1:60 split ratio.

\section{GC-MS analysis}

The compositions of leaf essential oils were analyzed with a Finnigan Trace GC-Polaris Q mass instrument (FinniganSpectronex) equipped with a fused-silica column $(30 \mathrm{~m} \times$
$0.25 \mathrm{~mm}$ i.d.) coated with DB-5 $\mathrm{ms}(\mathrm{df}=0.25 \mu \mathrm{m})$. The oven temperature was programmed as described above; injector temperature, $270^{\circ} \mathrm{C}$; ion-source temperature, $230^{\circ} \mathrm{C}$; carrier gas, He $(1 \mathrm{~mL} / \mathrm{min})$. The samples $(1 \mu \mathrm{L})$ were injected neat with a 1:60 split ratio, and the mass spectra (ionization energy, $70 \mathrm{eV}$ ) were recorded at $1 \mathrm{scan} / \mathrm{s}$ over the $m / z$ range 50-400 amu.

The percentage composition was computed by integrating the GC-FID peak area. The identification of the essential oil constituents was based on the comparison of their Kovats index (KI) determined relative to the retention times $\left(t_{R}\right)$ of a series of $n$-alkanes $\left(C_{9}-C_{24}\right)$ on the non-polar DB-5 ms column with those provided in the literature [13] and their mass spectra with those obtained with authentic standards available in the authors' laboratory and those of the NIST/NBS and Wiley spectra libraries.

\section{Mosquito larvae}

Larvae of Anopheles gambiae sensu stricto used in both laboratory and semi field trials were obtained from a laboratory colony at the insectary of Tropical Pesticide Research Institute (TPRI). Rearing of mosquito larvae in the laboratories was as described in other protocols [14]. The laboratory colony was maintained at photo phase of $12 \mathrm{~L}: 12 \mathrm{D}$ with temperature $27 \pm 2^{\circ} \mathrm{C}$ and relative humidity of $78 \pm 2 \%$. In both trials, third instar larvae were used as recommended by The World Health Organisation (WHO) protocol [15]. Tetramin fish food was used to feed the larvae.

\section{Laboratory larvae bioassay}

A test solution was prepared by dissolving $2 \mathrm{~mL}$ of emulsifier, dimethyl sulfoxide (DMSO), containing test essential oil in $98 \mathrm{~mL}$ normal laboratory larvae rearing water in plastic bowls of $100 \mathrm{~mL}$ capacity, which was shaken gently to ensure homogeneity followed by serial dilution to obtain 200, 100, 50, 25, and $12.5 \mu \mathrm{g} / \mathrm{mL}$ dosage as described by WHO larvae bioassay protocol [15]. The experiment was set for six replicates in each dosage and two controls; one containing normal laboratory larvae rearing water and the other one $1 \%$ aqueous solution of DMSO so as to assess its effect against larvae. Twenty third instar larvae were introduced in each replica and controls for larvicidal assay. Larvae were starved in both treatments and controls during the experiment. Mortality was observed and recorded at intervals of $12,24,48$, and $72 \mathrm{~h}$ post treatment, both dead and moribund larvae were counted as dead.

\section{Semi field larvae bioassay}

Similar dosages to laboratory larvae bioassays were evaluated in semi field larvae bioassays. The structures in the semi field environment were as described in other 
Table 1 The average mortality, $\mathrm{LC}_{50}$ and $\mathrm{LC}_{90}$ of $C$. japonica leaves essential oil against An. gambiae s.s. larvae in laboratory conditions

\begin{tabular}{cccccccccc}
\hline & $\mathbf{2 0 0}$ & $\mathbf{1 0 0}$ & $\mathbf{5 0}$ & $\mathbf{2 5}$ & $\mathbf{1 2 . 5}$ & Equation & $\mathbf{R}^{\mathbf{2}}$ & $\mathbf{L C}_{\mathbf{5 0}}$ & $\mathbf{L C}_{\mathbf{9 0}}$ \\
\hline $0 \mathrm{~h}$ & 0 & 0 & 0 & 0 & 0 & & & & \\
$12 \mathrm{~h}$ & 100 & 57 & 31 & 20 & 0 & $y=34.192 \mathrm{Ln}(\mathrm{x})-92.159$ & 0.9429 & 63.92 & 205.93 \\
$24 \mathrm{~h}$ & 100 & 77 & 58 & 38 & 9 & $y=31.884 \operatorname{Ln}(\mathrm{x})-68.329$ & 0.9941 & 40.90 & 143.42 \\
$48 \mathrm{~h}$ & 100 & 90 & 80 & 59 & 38 & $y=22.362 \operatorname{Ln}(\mathrm{x})-14.08$ & 0.9659 & 17.56 & 105.04 \\
$72 \mathrm{~h}$ & 100 & 98 & 92 & 87 & 80 & $y=7.3577 \operatorname{Ln}(\mathrm{x})+62.616$ & 0.9734 & 5.55 & 41.34 \\
\hline
\end{tabular}

studies [16]. The evaluation in the semi field environment adhered to the WHO protocol [15]. The dosages were replicated six times and their two controls; one containing normal laboratory larval rearing water and the other one $0.5 \%$ aqueous solution of DMSO were set. Twenty third instar larvae were introduced in each treatment and controls for larvicidal assay, then similar procedures to laboratory larvae bioassay were followed to accomplish the semi field larval bioassay.

\section{Statistical analysis}

To determine whether there was a statistically significant effect of $C$. japonica leaf essential oil against third instar larvae of An. gambiae s.s., Scheffe's multiple comparison procedure of SAS was used to analyse the percentage mortality and the results were expressed as mean \pm SD. Statistically significant results were those with $P<0.05$. Essential oil activity and toxicity reported as lethal concentration (in $\mu \mathrm{g} / \mathrm{mL}$ ), which caused 50 and $90 \%$ larval mortality were presented as $\mathrm{LC}_{50}$ and $\mathrm{LC}_{90}$ respectively, at $12,24,48$ and $72 \mathrm{~h}$ recording intervals.

\section{Results}

\section{Yield and chemical composition of essential oil}

The essential oil yield from C. japonica leaves was $17.06 \pm$ $0.56 \mathrm{~mL} / \mathrm{kg}$ with composition of $1.60 \pm 0.33 \%(\mathrm{w} / \mathrm{w})$ based on dry weight, the values are mean \pm standard deviation. Twenty two compounds were identified by GCMS chemical analysis representing about $98.09 \%$ of the essential oils, kau-16-rene being the most abundant with $23.29 \%$ followed by $\beta$-elemol with $18.29 \%$ composition, the remaining 20 chemicals range from $0.23-8.23 \%$ composition. All identified compounds were categorised into five groups with their relative abundances starting from the largest; oxygenated sesquiterpenes (39.01\%), monoterpene hydrocarbons (28.91\%), diterpene hydrocarbons (23.29\%), oxygenated monoterpenes $(6.47 \%)$ and sesquiterpenes hydrocarbons $(0.41 \%)$.

\section{Laboratory larval bioassay}

There was a remarkable increase in mortality (31.75 to $100 \%)$ when dosages were increased (12.5 to $200 \mu \mathrm{g} / \mathrm{mL}$ ), likewise with time (12 to $72 \mathrm{~h}$ ) mortality increased consistently $(41 \pm 5.0 \%$ to $91.4 \pm 12.5 \%$ ) (Table 1$)$. Furthermore

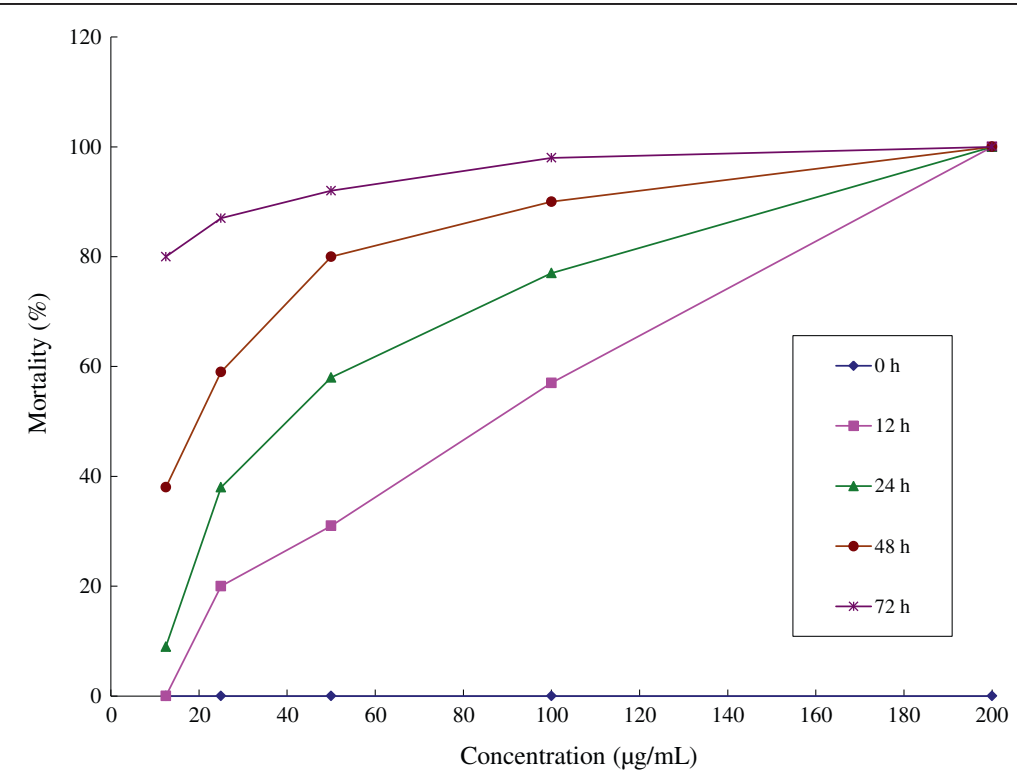

Figure 1 Anopheles gambiae s.s. larval mortality in the laboratory using different concentrations of Cryptomeria japonica at different time intervals. 
Table 2 The average mortality, $L C_{50}$ and $L C_{90}$ of $C$. japonica leaf essential oil against An. gambiae s.s. in semi field conditions

\begin{tabular}{cccccccccc}
\hline & $\mathbf{2 0 0}$ & $\mathbf{1 0 0}$ & $\mathbf{5 0}$ & $\mathbf{2 5}$ & $\mathbf{1 2 . 5}$ & Equation & $\mathbf{R}^{\mathbf{2}}$ & $\mathbf{L C}_{\mathbf{5 0}}$ & $\mathbf{L C}_{\mathbf{9 0}}$ \\
\hline $0 \mathrm{~h}$ & 0 & 0 & 0 & 0 & 0 & & & & \\
$12 \mathrm{~h}$ & 98 & 15 & 0 & 1 & 0 & $y=0.6786 \mathrm{x}-41.5$ & 0.964 & 134.84 & 213.11 \\
$24 \mathrm{~h}$ & 100 & 53 & 33 & 13 & 0 & $y=34.625 \operatorname{Ln}(\mathrm{x})-95.653$ & 0.9371 & 67.13 & 193.78 \\
$48 \mathrm{~h}$ & 100 & 94 & 82 & 44 & 15 & $y=31.739 \operatorname{Ln}(\mathrm{x})-57.165$ & 0.9174 & 29.27 & 103.21 \\
$72 \mathrm{~h}$ & 100 & 100 & 96 & 76 & 56 & $y=21.929 \operatorname{Ln}(\mathrm{x})+3.8134$ & 0.9377 & 8.22 & 50.92 \\
\hline
\end{tabular}

$\mathrm{LC}_{50}$ and $\mathrm{LC}_{90}$ values were found to be 63.92 and $205.93 \mu \mathrm{g} / \mathrm{mL}$ (after $12 \mathrm{~h}$ ); 40.90 and $143.42 \mu \mathrm{g} / \mathrm{mL}$ (after $24 \mathrm{~h}$ ); 17.56 and $104.04 \mu \mathrm{g} / \mathrm{mL}$ (after $48 \mathrm{~h}$ ); 5.55 and $41.34 \mu \mathrm{g} / \mathrm{mL}$ (after $72 \mathrm{~h}$ ), respectively (Table 1 ). Figure 1 shows trends of mortality increase with increased concentration at different mortality recording intervals. Controls did not reveal the effect on larvae. Therefore, data pertaining to larvicidal activity of C. japonica leaf essential oil against third instar larvae of An. gambiae s.s were statistically significant $(P<0.0001)$ based on both dosages and time $\left(R^{2}=0.97\right)$.

\section{Semi field larval bioassay}

Mortality increased (17.75 to $99.5 \%$ ) with increased dosages $(12.5$ to $200 \mu \mathrm{g} / \mathrm{mL})$, it was also found that at each successive recording interval (12 to $72 \mathrm{~h}$ ), mortality increased (22.80 to $85.60 \%$ ) considerably (Table 1 ). $\mathrm{LC}_{50}$ and $\mathrm{LC}_{90}$ values (Table 2 ) were determined at different time recording intervals. The results indicated larvicidal effect of leaf essential oil at $12 \mathrm{~h}\left(\mathrm{LC}_{50}=134.84 \mu \mathrm{g} / \mathrm{mL} ; \mathrm{LC}_{90}=213\right.$. $11 \mu \mathrm{g} / \mathrm{mL}), 24 \mathrm{~h}\left(\mathrm{LC}_{50}=67.13 \mu \mathrm{g} / \mathrm{mL} ; \mathrm{LC}_{90}=193.78 \mu \mathrm{g} /\right.$ $\mathrm{mL}), 48 \mathrm{~h}\left(\mathrm{LC}_{50}=29.27 \mu \mathrm{g} / \mathrm{mL} ; \mathrm{LC}_{90}=103.21 \mu \mathrm{g} / \mathrm{mL}\right)$ and
$72 \mathrm{~h}\left(\mathrm{LC}_{50}=8.22 \mu \mathrm{g} / \mathrm{mL} ; \mathrm{LC}_{90}=50.92 \mu \mathrm{g} / \mathrm{mL}\right)$ (Table 2). There was no conspicuous effect against larvae in the controls. The mortality trend based on dosage and time are described (Figure 2). Data recorded showed that leaf essential oil examined in semi field condition exhibited noticeable larvicidal performance.

\section{Discussion}

Insecticides of plant origin are the focus in the struggle to combat developing insect resistance to synthetic insecticides, like DDT, and the associated challenges such as residual problems in the environment and effect on nontarget organisms. In contrast, insecticides of plant origin do not render residual problems to the environment, do not harm non-targeted organisms and are still capable of suppressing pest populations. Although a number of compounds of plant origin are currently reported $[10,17]$, need for the discovery of more effective plant products is of paramount importance so as to improve insecticide formulation and develop environmentally acceptable insecticides in order to replace conventional insecticides in the control of mosquitoes [18].

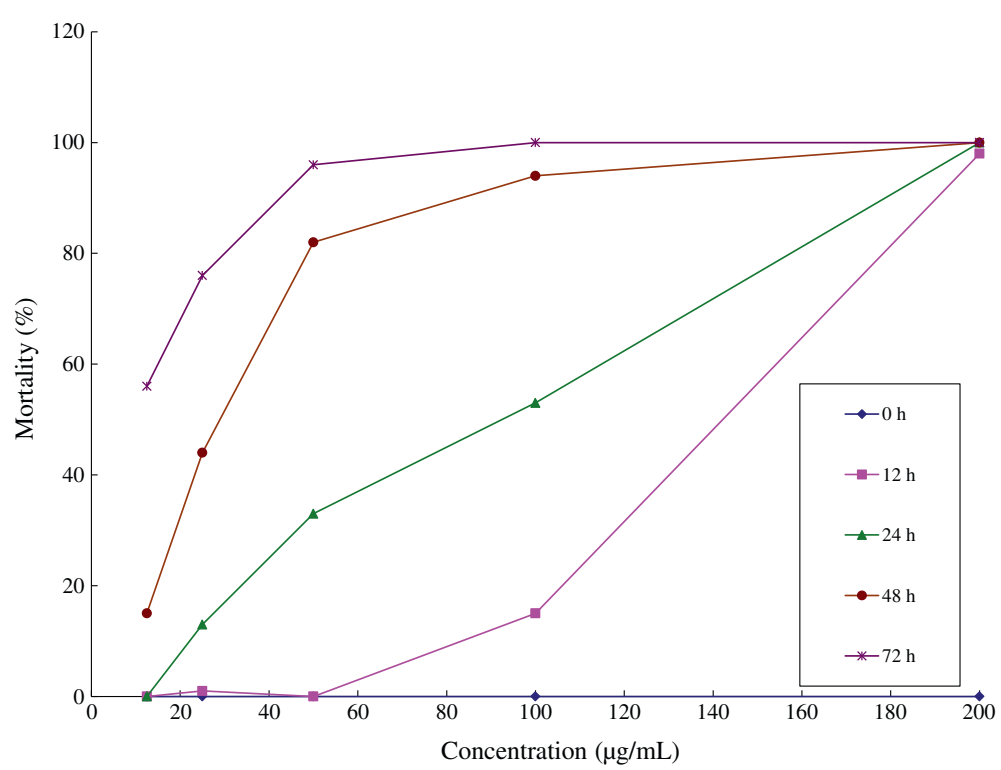

Figure 2 Anopheles gambiae s.s. larval mortality in a semifield environment using different concentrations of Cryptomeria japonica at different time intervals. 
In this study, leaf essential oil from 28-year-old Japanese cedars (C. japonica D. Don) was explored for its composition and larvicidal performance. Twenty-two compounds were identified by GC-MS chemical analysis representing about $98.09 \%$ of the essential oil. Kau-16-rene was the most abundant with $23.29 \%$ followed by $\beta$-elemol with $18.29 \%$ composition (Figure 2). In contrary to the findings of this study, Wang and others identified $\beta$-elemol (18.22\%) as a dominant compound [17]; Shieh and others identified $\beta$-eudesmol (14.67\%), $\alpha$-eudesmol (14.67\%) and $\beta$-elemol (11.62\%) as major compounds in C. japonica leaf essential oil [19]. This discrepancy might be due to tree age difference, season of sample collection or other factors [10,20].

The leaf essential oil of $C$. japonica was found to exhibit great larvicidal performance against third instar larvae of malaria vectors, An. gambiae s.s. Data obtained revealed an increase in larvae mortality with increased concentration of the essential oil solution. Mortality in laboratory conditions increased from $31.75 \%$ to $100 \%$ at dosage increase of $12.5 \mu \mathrm{g} / \mathrm{mL}$ to $200 \mu \mathrm{g} / \mathrm{mL}$ respectively. The $\mathrm{LC}_{50}$ and $\mathrm{LC}_{90}$ values were 63.92 and $205.93 \mu \mathrm{g} / \mathrm{mL}$ (at $12 \mathrm{~h}$ ); 40.90 and $143.42 \mu \mathrm{g} / \mathrm{mL}$ (at $24 \mathrm{~h}$ ); 17.56 and $105.04 \mu \mathrm{g} / \mathrm{mL}$ (at $48 \mathrm{~h}$ ); 5.55 and $41.34 \mu \mathrm{g} / \mathrm{mL}$ (at $72 \mathrm{~h}$ ). In semi field conditions, mortality increased from $17.5 \%$ to $99.5 \%$ at a similar dosage increase, the $\mathrm{LC}_{50}$ and $\mathrm{LC}_{90}$ values were 134.84 and $213.11 \mu \mathrm{g} / \mathrm{mL}$ (at $12 \mathrm{~h}$ ); 67.13 and $193 \mu \mathrm{g} / \mathrm{mL}$ (at $24 \mathrm{~h}$ ); 29.27 and $103.21 \mu \mathrm{g} / \mathrm{mL}$ (at $48 \mathrm{~h}$ ); 8.22 and $50.92 \mu \mathrm{g} / \mathrm{mL}$ (at $72 \mathrm{~h}$ ). Therefore, mortality in the laboratory was significantly higher than in semi field conditions, this might be attributed to the exposure of larvicides under sunlight, which might have broken it down into nontoxic products [16]. To get rid of such environmental challenges, botanical larvicides need a continued application for its effective control of mosquito larvae [21]. Essential oil activity may be influenced by the presence of major constituents like kau-16-rene (23.29\%) and $\beta$-elemol (18.29\%), however, [22] reported that minor compounds can also be responsible for larvicidal performance.

Previous studies have revealed the mode of action of C. japonica leaf essential oil and that it provides inhibitory performance against Aedes aegypti and Ae. albopictus larval development hormone [10], therefore, increased concentration of essential oil offered more growth inhibition and subsequently higher larval mortality which was revealed using $A n$. gambiae s.s. larvae in this study.

\section{Conclusions}

The findings of this study have shown high larval mortality induced by $C$. japonica leaf essential oil against $A n$. gambiae senso stricto, a main malaria vector. However, further studies are needed to assess the effect of individual compounds in both laboratory and semi field conditions on larval mortality and the mechanisms involved.

\section{Abbreviations}

GC-MS: Gas chromatography-mass spectrometry;

DDT: Dichlorodiphenyltrichloroethane; DMSO: Dimethyl sulfoxide; WHO: World health organisation; KI: Kovats index; GC-FID: Gas

chromatography with flame ionization detector; LC: Lethal concentration.

\section{Competing interests}

The authors declare that they have no competing interests.

\section{Authors' contributions}

EJK, FPM and SSC designed the study. STC, SSC, EJK and FPM analysed and interpreted the data. FPM and LL carried out data collection and entry. FPM EJK and STC wrote the manuscript. The manuscript was critically revised by EJK, GN, SSC and STC. The final version of the manuscript was accepted and approved by all authors.

\section{Acknowledgements}

Thanks to Esther Lyatuu and Adrian Massawe for rearing mosquito larvae and data collection assistance. Authors would like to thank the Tropical Pesticides Research Institute (TPRI) for provision of her infrastructures for these experiments. Magreth F. Shayo is acknowledged for her valuable comments and suggestions during write up of this manuscript. This manuscript is published with permission from TPRI director general.

\section{Author details}

${ }^{1}$ Department of Zoology and Wildlife Conservation, College of Natural and Applied Sciences, University of Dar-es-salaam, P.O. Box 35165, Dar-es-salaam, Tanzania. ${ }^{2}$ Experimental Forest, National Taiwan University, Nan-Tou 557, Taiwan. ${ }^{3}$ Division of Livestock and Human Diseases Vector Control, Tropical Pesticides Research Institute, Ngaramtoni, Off Nairobi Road, P.O. Box 3024, Arusha, Tanzania. ${ }^{4}$ School of Forestry and Resource Conservation, National Taiwan University, No. 1, Sec.4, Roosevelt Road, Taipei 106, Taiwan.

${ }^{5}$ Department of Medical Parasitology and Entomology, Catholic University of Health and Allied Sciences, P.O. Box 1464, Mwanza, Tanzania.

Received: 2 May 2014 Accepted: 1 September 2014

Published: 4 September 2014

\section{References}

1. Coluzzi M: The clay feet of the malaria giant and its African roots: hypotheses and inferences about origin, spread and control of Plasmodium falciparum. Parassitologia 1999, 41:277-283.

2. WHO: World Malaria Report 2013. 20 Avenue Appia, 1211 Geneva 27, Switzerland: World Health Organization; 2013.

3. Sinka M, Rubio-Palis Y, Manguin S, Patil A, Temperley W, Gething P, Van Boeckel T, Kabaria C, Harbach R, Hay S: The dominant Anopheles vectors of human malaria in the Americas: occurrence data, distribution maps and bionomic precis. Parasit Vectors 2010, 3:72.

4. Czeher C, Labbo R, Arzika I, Duchemin JB: Evidence of increasing Leu-Phe knockdown resistance mutation in Anopheles gambiae from Niger following a nationwide long-lasting insecticide-treated nets implementation. Malar J 2008, 7:189.

5. Killeen GF, Fillinger U, Knols BG: Advantages of larval control for African malaria vectors: low mobility and behavioural responsiveness of immature mosquito stages allow high effective coverage. Malar J 2002, 1:8.

6. Labbe P, Alout H, Djogbe Nou L, Weill M, Pasteur N: Evolution of resistance to insecticide in disease vectors. In Genetics and Evolution of Infectious Diseases. Edited by Tibayrenc M. London: Elsevier Inc; 2011:363-409.

7. Dua V, Kumar A, Pandey A, Kumar S: Insecticidal and genotoxic activity of Psoralea corylifolia Linn. (Fabaceae) against Culex quinquefasciatus Say, 1823. Parasit Vectors 2013, 6:30

8. George D, Finn R, Graham K, Sparagano O: Present and future potential of plant-derived products to control arthropods of veterinary and medical significance. Parasit Vectors 2014, 7:28.

9. Liu C, Mauk MG, Hart R, Bonizzoni M, Yan G, Bau HH: A low-cost microfluidic chip for rapid genotyping of malaria-transmitting mosquitoes. PLoS One 2012, 7:e42222.

10. Cheng S-S, Chua M-T, Chang E-H, Huang C-G, Chen W-J, Chang S-T: Variations in insecticidal activity and chemical compositions of leaf essential oils from Cryptomeria japonica at different ages. Biores Technol 2009, 100:465-470. 
11. Kannathasan $\mathrm{K}$, Senthilkumar A, Venkatesalu V: Mosquito larvicidal activity of methyl-p-hydroxybenzoate isolated from the leaves of Vitex trifolia Linn. Acta Trop 2011, 120:115-118.

12. Cheng S-S, Lin H-Y, Chang S-T: Chemical composition and antifungal activity of essential oils from different tissues of Japanese cedar (Cryptomeria japonica). J Agric Food Chem 2005, 53:614-619.

13. Adams RP: Identification of Essential Oil Components by Gas Chromatography/ Quadrupole Mass Spectroscopy. Illinois: Allured; 2001.

14. Balestrino F, Benedict MQ, Gilles JRL: A New larval tray and rack system for improved mosquito mass rearing. J Med Entomol 2012, 49:595-605

15. World Health Organization: 2005. http://whqlibdoc.who.int/hq/2005/ WHO_CDS_WHOPES_GCDPP_2005.13.pdf. Guidelines for laboratory and field testing of mosquito larvicides.

16. Kweka EJ, Nyindo M, Mosha F, Silva AG: Insecticidal activity of the essential oil from fruits and seeds of Schinus terebinthifolia Raddi against African malaria vectors. Parasit Vectors 2011, 4:129.

17. Wang S-Y, Lai W-C, Chu F-H, Lin C-T, Shen S-Y, Chang S-T: Essential oil from the leaves of Cryptomeria japonica acts as a silverfish (Lepisma saccharina) repellent and insecticide. J Wood Sci 2006, 52:522-526.

18. Alkofahi A, Rupprecht JK, Anderson JE, Mclaughlin JL, Mikolajczak KL, Scott BA: Search for new pesticides from higher plants. In Insecticides of Plant Origin. Edited by Arnason JT, Philogene BJR, Morand P. Washington, DC: American Chemical Society; 1989:25-43.

19. Shieh B, Lizuka Y, Matsubara Y: Monoterpenoid and sesquiterpenoid constituents of the essential oil of sugi (Cryptomeria japonica D. Don.). Agric Biol Chem 1981, 45:1493-1495.

20. Daferera DJ, Ziogas BN, Polissiou MG: GC-MS analysis of essential oils from some Greek aromatic plants and their fungitoxicity on Penicillium digitatum. J Agric Food Chem 2000, 48:2576-2581.

21. Yang Y-C, Lee S-G, Lee H-K, Kim M-K, Lee S-H, Lee H-S: A piperidine amide extracted from Piper longum L. fruit shows activity against Aedes aegypti mosquito larvae. J Agric Food Chem 2002, 50:3765-3767.

22. Silva WJ, Dória GAA, Maia RT, Nunes RS, Carvalho GA, Blank AF, Alves PB, Marçal RM, Cavalcanti SCH: Effects of essential oils on Aedes aegypti larvae: alternatives to environmentally safe insecticides. Biores Technol 2008, 99:3251-3255.

doi:10.1186/1756-3305-7-426

Cite this article as: Mdoe et al.: Larvicidal efficacy of Cryptomeria

japonica leaf essential oils against Anopheles gambiae. Parasites \& Vectors 2014 7:426.

\section{Submit your next manuscript to BioMed Central and take full advantage of:}

- Convenient online submission

- Thorough peer review

- No space constraints or color figure charges

- Immediate publication on acceptance

- Inclusion in PubMed, CAS, Scopus and Google Scholar

- Research which is freely available for redistribution 